Provided for non-commercial research and education use. Not for reproduction, distribution or commercial use.

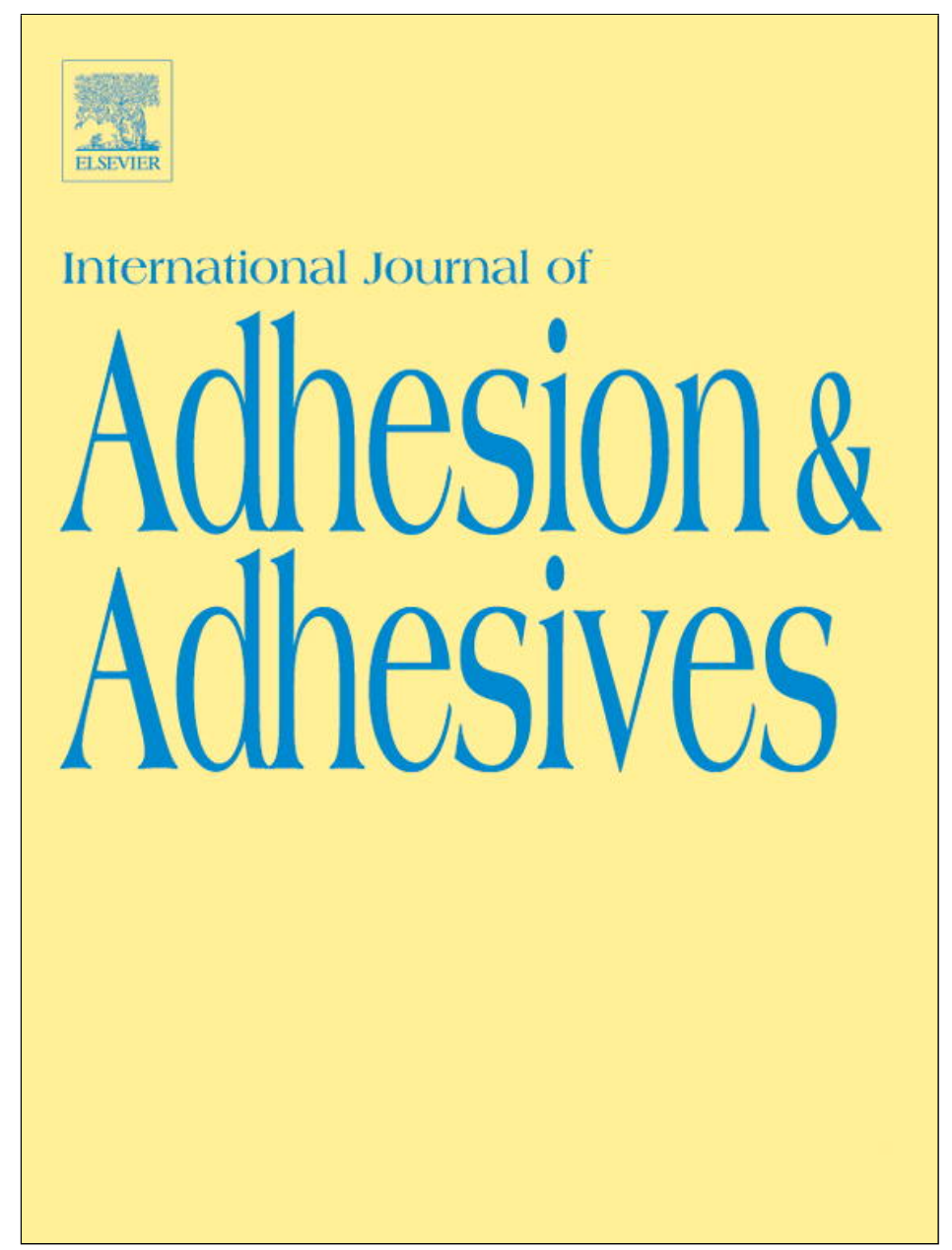

(This is a sample cover image for this issue. The actual cover is not yet available at this time.)

This article appeared in a journal published by Elsevier. The attached copy is furnished to the author for internal non-commercial research and education use, including for instruction at the authors institution and sharing with colleagues.

Other uses, including reproduction and distribution, or selling or licensing copies, or posting to personal, institutional or third party websites are prohibited.

In most cases authors are permitted to post their version of the article (e.g. in Word or Tex form) to their personal website or institutional repository. Authors requiring further information regarding Elsevier's archiving and manuscript policies are encouraged to visit:

http://www.elsevier.com/copyright 


\title{
Durability of adhesion between an adhesive and post-space dentin: Push-out evaluation at one and six months
}

\author{
Ilaria Ballesio ${ }^{a}$, Vincenzo Angotti ${ }^{a}$, Gianni Gallusi ${ }^{a}$, Antonio Libonati ${ }^{a}$, Simona Tecco ${ }^{\mathrm{b}, *, 1}$, \\ Giuseppe Marzo ${ }^{\mathrm{b}, *}$, Vincenzo Campanella ${ }^{\mathrm{a}}$ \\ a Unit of Restorative Dentistry, University of Rome Tor Vergata, Rome, Italy \\ ${ }^{\mathrm{b}}$ Department of Health Science, School of Orthodontics, University of L'Aquila, Italy
}

\section{A R T I C L E I N F O}

\section{Article history:}

Accepted 14 April 2012

Available online 7 May 2012

Keywords:

Push-out test

Adhesion

Post-space

Fiber post

Longevity

\begin{abstract}
S U M M A R Y
Aims: The aim of this study was to investigate, by means of the push-out test, the bond of Prime \& Bond NT at various post-space dentin locations and the influence of time of water storage on bond strength values.

Methods: 30 single-rooted teeth were used for the bond strength measurement. In each tooth fiber posts were cemented with the commercial bonding system "Prime \& Bond NT" in combination with the resin-based filling material "Opticore Cure Core Composite". After $24 \mathrm{~h}$ (group A: 10 roots), 1 month (group B: 10 roots), and 6 months (group C: 10 roots) of water storage, the specimens were sectioned in $1 \mathrm{~mm}$-thick slices for the push-out test. The data were divided into three regions (coronal/middle/ apical) and analyzed using Kruskal-Wallis Test and Mann-Whitney U Test $(\mathrm{p}<0.05)$.

Results: The bond strength values registered did not show statistically significant differences within group A and C; within group B statistically significant differences were found between the coronal and the middle thirds and between the coronal and the apical third. The apical bond strength values did not show any statistically significant difference among the three groups (Kruskal-Wallis test); in the middle thirds a statistically significant difference was found at 6 months when compared with the $24 \mathrm{~h}$ and 1 -month samples. In the coronal thirds was found a statistically significant difference between 1 month and 6 months. Analysis of the specimens under optical microscope revealed a prevalence of adhesive failures between fiber post and root dentin.

Conclusions: Bond strength values are lower at the apical third. Over time the adhesion of the fiberpost/ luting cement/post-space dentin does not remain stable.
\end{abstract}

(c) 2012 Elsevier Ltd. All rights reserved.

\section{Introduction}

Most clinical failures involving endodontically treated teeth restored with fiber post occur through debonding [1]. The bond strength between the resin luting cement and the post-space dentin is conditioned by the different distribution of the adhesive system along the post-space, by the anatomic and histologic characteristics of the root canal, including the orientation of the dentinal tubules [2], and by a non-uniform dentin hybridization in the apical third [3]. Furthermore, the control of moisture after the application and removal of phosphoric acid and the incomplete infiltration of the resin into the dentin significantly condition bond strength [4].

\footnotetext{
* Corresponding authors at: Department of Health Science, University of L'Aquila, Italy.

E-mail address: simtecc@unich.it (S. Tecco).

${ }^{1}$ Simona Tecco corrected the text, analyzed and revised the data and the interpretation of results.
}

The long-term durability of the adhesive interface is an important factor that conditions the integrity of the restoration regarding all adhesives systems [5,6]. A direct water exposure of the resindentin interface for prolonged periods results in decreased bond strength, independent of the adhesive system used [6].

The aim of this study was to investigate, by means of the pushout test, the bond of a commercial adhesive system at various post-space dentin locations and the influence of water storage of 1 month and 6 months on bond strength values.

\section{Materials and methods}

\subsection{Tooth preparation}

30 single-rooted teeth extracted for periodontal reasons were selected and stored in 0.5 chloramine $\mathrm{T}$ [7] and used within 6 months from extraction. The crown surfaces of each tooth were sectioned below the cemento-enamel junction perpendicular to 
their long axis with a diamond bur under copious water cooling. The roots were endodontically instrumented with rotary Ni-Ti instruments Mtwo (Sweden \& Martina, Padua, Italy). During the cleaning and shaping of the root canal, a rinse was performed at each change of instrument with $5 \%$ sodium hypochlorite (Ogna, Milan, Italy) and 10\% EDTA irrigation (Ogna, Milan, Italy), using sodium hypochlorite for the last irrigation. The prepared root canals were obturated with manual vertical condensation with non-standardized gutta-percha points (Inline, Turin, Italy) and endodontic sealer (Pulp Canal Sealer EWT, Kerr, Romulus, MI).

\subsection{Bonding of fiber posts}

After $48 \mathrm{~h}$ storage in a saline solution, post spaces were prepared to a depth of $7 \mathrm{~mm}$ measured from the sectioned surfaces using a post drill of $1.2 \mathrm{~mm}$ diameter (Endoclass, IDS, Savona, Italy). Every canal was etched with $37 \%$ phosphoric acid (Total etch, Ivoclar Vivadent). The gel was introduced in the canal through a needle, and after $60 \mathrm{~s}$ the gel was rinsed with an endodontic syringe $[7,8]$. Excess water was removed from the post-space with a gentle blowing of air and with paper points, leaving the dentin slightly moist. A microbrush was used to introduce the adhesive (Prime \& Bond NT, Kerr, Romulus, MI). After $20 \mathrm{~s}$ excess adhesive was removed through a clean microbrush. The adhesive applied was polymerized for $60 \mathrm{~s}$ with a halogen lamp (Coltolux, Coltene). The fiber posts (Endoclass, IDS, Savona, Italy) were acid etched with $37 \%$ phosphoric acid (Total etch, Ivoclar Vivadent) for $60 \mathrm{~s}$ [7]. After rinsing, the adhesive (Prime \& Bond NT, Kerr, Romulus, MI) was applied with a microbrush, the excess was removed with a gentle blowing of air, and the adhesive was polymerized for $60 \mathrm{~s}$ with a halogen lamp (Coltolux, Coltene). The luting cement (Opticore Cure Core Composite, IDS, Savona, Italy) was injected into the canal with a Composite-Gun and an appropriate needle. The posts were then seated to full depth in the prepared spaces using finger pressure. The excess of the luting agent was immediately removed with a small brush. The resin luting agent was light polymerized for $60 \mathrm{~s}$ with halogen light (Coltolux, Coltene). A microhybrid composite (Enamel, Mycerium, Genoa, Italy) was used for the execution of a $2 \mathrm{~mm}$ build-up.

Specimens were then randomly divided and stored in the saline solution for $24 \mathrm{~h}$ (group A), 1 month (group B), and 6 months (group C).

\subsection{Push-out test}

Immediately prior to the respective periods of bond strength testing, the specimens were sectioned perpendicular to the long axis under water cooling with a low-speed saw (Micromet M; Remet Spa, Casalecchio di Reno, Italy). Six $1 \mathrm{~mm}$-thick slabs were obtained per root and identified as cervical (two slabs), middle (two slabs), and apical (two slabs). Each slice was marked on its coronal side with an indelible marker.

For the push-out test each section was fixed with cianoacrilate (Super Attak Gel, Henkel Loctite Adesivi S.r.l., Milan, Italy) to a custom-made push-out jig, ensuring that the coronal surface faced the jig and the post was centered over the hole in the jig. The push-out jig was placed on an Instron 3344 universal testing machine with a cell load of $1000 \mathrm{~N}$ (Fig. 1). Load was applied at a crosshead speed of $0.5 \mathrm{~mm} / \mathrm{min}$ until the post was dislodged. The maximum failure load (Table 1 ) was recorded in $\mathrm{N}$ and converted to MPa according to the following formula:

$M P a=N / 2 \pi r X h$

Statistical analysis was performed applying the Kruskal-Wallis Test and Mann-Whitney $U$ test for the bond strength evaluation
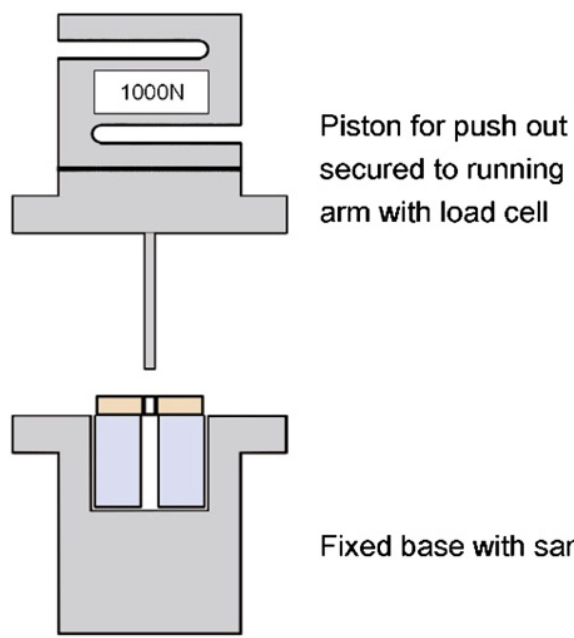

Fixed base with sample

Fig. 1. Instron machine to evaluate the push-out strength at the three levels (coronal section, middle section and apical section of the root canal). The thin section of the root is positioned perpendicular to the direction of the pushout force.

Table 1

Mean bond strength, standard deviation and statistical significance.

\begin{tabular}{llll}
\hline & Coronal & Middle & Apical \\
\hline $24 \mathrm{~h}$ & $9.81 \pm 6.83 \mathrm{a} 1.2$ & $5.74 \pm 5.21 \mathrm{a} 1$ & $4.82 \pm 4.83 \mathrm{a} 1$ \\
1 month & $9.67 \pm 3.81 \mathrm{a} 1$ & $5.65 \pm 5.05 \mathrm{~b} 1$ & $2.33 \pm 3.03 \mathrm{~b} 1.2$ \\
6 months & $7.24 \pm 4.85 \mathrm{~b} 2$ & $2.03 \pm 1.44 \mathrm{a} 2$ & $2.39 \pm 3.05 \mathrm{a} 2$
\end{tabular}

Bond strength values are expressed in MPa. For each row: values with different letters indicate statistically significant differences $(p<0.05)$; for each column: different numbers indicate statistically significant differences $(p<0.05)$.

among root thirds $(\mathrm{p}<0.05)$ and for bond strength evaluation at different storage time $(\mathrm{p}<0.05)$.

After push-out testing, the specimens were analyzed by an optical microscope to determine the failure mode [10,27-29]: type I, adhesive between resin cement and fiber post; type II, mixed (failure occurring at resin cement/fiber post interface and at resin cement/dentin interfaces in the same specimen); and type III, adhesive between resin cement and root dentin.

\section{Results}

For specimens that prematurely failed the bond strength was registered as zero and was not included in the statistical analysis. A general agreement on how to statistically treat the prematurely failed specimens during microtensile bond strength testing is presently lacking in the literature. They may be excluded, considered as zero or greater than zero values. In the present study, it was decided to exclude the prematurely failed slices to the statistical analysis.

The bond strength values registered did not show any statistically significance difference (Kruskal-Wallis test) within groups A and C (Table 1). Within group B bond strength values, a statistically significant difference (Kruskal-Wallis test) was found; the significant difference in this group (Mann-Whitney $U$ test) was observed between bond strength values of coronal third and middle third and between coronal third and apical third (Table 1).

The apical bond strength values did not show any statistically significant difference among the three groups (Kruskal-Wallis test); the Mann-Whitney U test showed a statistically significant difference between $24 \mathrm{~h}$ and 6 months. The middle bond strength values showed a statistically significant difference among the 
three groups (Kruskal-Wallis test); the Mann-Whitney U test showed a statistically significant difference between $24 \mathrm{~h}$ and 6 months and between 1 month and 6 months. The coronal bond strength values did not show any statistically significant difference among the three groups (Kruskal-Wallis test); the MannWhitney $U$ test showed a statistically significant difference between 1 month and 6 months (Table 1).

Analysis of the specimens under the optical microscope revealed that there was no adhesive failure between fiber post and resin cement. A prevalence of adhesive failures between fiber post and root dentin was observed.

\section{Discussion}

The object of this investigation was to compare the regional bond strength of the commercial adhesive Prime\&BondNt with root canal dentin and determine the bond resistance of resin-root dentin to degradation after 1 month and 6 months of water storage.

Most in vitro post and core experiments have been accomplished evaluating the tensile force or pulling force to remove the post from the root canals [10]. However, this rarely occurs clinically. The microtensile method of adhesion testing permits a more uniform stress distribution along the bonded interface [11]. Furthermore, this technique enables the measurement of bond strength to very small areas and allows the assessment of regional differences of adhesion at the three levels of the root canals [12]. The trimming version presents an extremely high number of premature failures due to the uncontrolled stress applied on the bonded interfaces during sample preparation [13]. In non-trimming technique studies the measurement of bond strength has been conducted either between resin cement and just one side of the root dentin [12] or between fiber post and resin cement $[1,14]$. The push-out test seems to be the most accurate and reliable technique to measure the bonds of fiber posts to root dentin [13].

The push-out force increases with increased thickness of dentin disk [15]. The optimal thickness of dentin disk is still controversial, with values ranging from 4 to $1 \mathrm{~mm}[13,15-17]$. In the present study $1 \mathrm{~mm}$ disks were used, since the use of thicker disks seems to increase the area of friction and may lead to an overestimation of the bond strength.

In agreement with the literature [9,18], the highest bond strength values of the tested material were found in the coronal samples in all groups. The premature failures occurred in the present study were observed in the apical thirds in all groups in the last apical slice. This may be related to a difficult accessibility of the middle and apical thirds of the root canal with a lower control of the humidity and a lower conversion degree [19]. Moreover, it has been shown that the control of moisture after the application and removal of phosphoric acid and the incomplete infiltration of the resin into the dentin significantly affect bond strength [20].

The best method for simulating in vivo conditions is yet to be determined [21]; the different aging methods of the adhesive interfaces, such as thermal stresses, chemical attacks, masticatory forces, or their combination, cannot actually replace the effects of time. The most commonly used artificial aging technique is longterm water storage. The bonded specimens are stored in fluid at $37{ }^{\circ} \mathrm{C}$ for a specific period that may vary from a few months [20] up to 4-5 years or even longer. The storage solution may be used alone [8] or impleted with antibacterial substances such as chloramine $\mathrm{T}$ [7], sodium azide [5], or thymol (Phrukkanon et al., 1999).
Degradation studies on adhesives interfaces have focused mainly on coronal [7,19], or cervical dentin [22]; the resin-dentin bond strength reductions and the resistance of the resin-dentin interface to degradation observed are dependent on the different adhesives systems tested [5], the degree of conversion [19], or the presence of a peripheral rim of resin bonded enamel [5,7].

A decrease in bonding effectiveness is usually supposed to be determined by hydrolysis of interface components (resin and/or collagen). Water can infiltrate in the resin matrix and reduce the mechanical properties of the polymer chains, in a process known as plasticization $[23,24]$. Furthermore, some interface components such as uncured monomers or break-down products can be eluted and can weaken the bond [25].

In agreement with the literature [20,26], the bond strength values of the tested adhesive system to radicular dentin observed over time showed a significant reduction.

In this study water storage was assessed without thermal and load cycling, for more similarities to the oral conditions it is recommended to perform fatigue test in combination with water storage.

\section{Conclusions}

Whitin the limitations of the present investigation it may be concluded that:

1) bond strength values appeared lower at the apical third.

2) the push-out strength of fiber post was significantly influenced by a time of water storage. Over time the adhesion of the fiberpost/luting cement/post-space dentin does not remain stable. Considering the fact that post-core complex is not directly exposed to oral fluids in vivo and that water exposure usually occurs after leakage: the times assessed could be attributed to longer times in vivo. Howewer, the manner in which the fiber post in $1 \mathrm{~mm}$-thick root slice is exposed to dislodging force during push-out testing cannot be directly compared with functional force that the post needs to withstand during clinical service.

\section{References}

[1] Aksornmuang J, Foxton RM, Nakajima M, Tagami J. Microtensile bond strength of a dual-cure resin core material to glass and quartz fibre posts. J Dent 2004;32:443-50.

[2] Mannocci F, Pilecki P, Bertelli E, Watson T. Density of dentinal tubules affects the tensile strength of root dentin. Dent Mater 2004:20:293-6.

[3] Vichi A, Grandini S, Davidson CL, Ferrari M. An SEM evaluation of several adhesive systems used for bonding fiber posts under clinical conditions. Dent Mater 2002;18:495-502.

[4] Tay FR, Gwinnett AJ, Wei SH. The overwet phenomenon: an optical, micromorphological study of surface moisture in the acid-conditioned, resindentin interface. Am J Dent 1996;9:43-8.

[5] Osorio R, Pisani-Proenca J, Erhardt MCG, Osorio E, Aguilera FS, Tay FR, et al. Resistance of ten contemporary adhesives to resin-dentine bond degradation. J Dent 2008;36:163-9.

[6] Torkabadi S, Nakajima M, Ikeda M, Foxton RM, Tagami J. Bonding durability of HEMA-free and HEMA-containing one-step adhesives to dentine surrounded by bonded enamel. J Dent 2008;36:80-6.

[7] Gamborgi GP, Loguercio AD, Reis A. Influence of enamel border and regional variability on durability of resin-dentine bonds. J Dent 2007;35:371-6.

[8] Baldissara P, Zicari F, Calandro LF, Scotti R. Effect of root canal treatments on quartz fiber posts bonding to root dentin. J Endod 2006;32:985-8.

[9] Faria Silva AL, Casselli DS, Ambrosano GM, Martins LR. Effect of the adhesive application mode and fiber post translucency on the push-out bonds strength to dentin. J Endod 2007;33:1078-81.

[10] Giacchetti L, Scaminaci Russo D, Bertini F, Giuliani V. Translucent fiber post cementation using a light-curing adesive/composite system: SEM analysis and pull-out test. J Dent 2004;32:629-34.

[11] Pashley DH, Carvalho RM, Sano H, Nakajima M, Yoshiyama M, Shono Y, et al. The microtensile bond test: a review. J Adhes Dent 1999;1:299-309. 
[12] Bouillaguet S, Troesch S, Wataha JC, Krejci I, Meyer JM, Pashley DH. Microtensile bond strength between adhesive cements and root canal dentin. Dent Mater 2003:19:199-205.

[13] Goracci C, Tavares AU, Fabianelli A, Monticelli F, Raffaelli O, Cardoso PC, et al. The adhesion between fiber posts and root canal walls: comparison between microtensile and push-out bond strength measurements. Eur J Oral Sci 2004;112:353-61.

[14] Vano M, Goracci C, Monticelli F, Tognini F, Gabriele M, Tay FR, et al. The adhesion between fiber posts and composite resin cores the evaluation of microtensile bond strength following various surface chemical treatments to posts. Int Endod J 2006;39:31-9.

[15] Le Bell AM, Lassila LV, Kangasniemi I, Vallitu PK. Bonding of fibre reinforced composite post to root canal dentin. J Dent 2005;33:533-9.

[16] Muniz L, Mathias P. The influence of sodium hypochlorite and root canal sealers on postretention in different dentin regions. Oper Dent 2005;30: 533-9.

[17] Bolhuis P, De Gee A, Feilzer A. The influence of fatigue loading on the quality of the cement layer and retention strength of carbon fiber post resin composite core restorations. Oper Dent 2005;30:220-7.

[18] Nagas E, Cehreli ZC, Durmaz V, Vallittu PK, Lassila LVJ. Regional push-out bond strength and coronal microleakage of resilon after different light-curing methods. J Endod 2007:33:1464-8.

[19] Cadenaro M, Antoniolli F, Sauro S, Tay FR, Di Lenarda R, Prati C, et al. Degree of conversion and permeability of dental adhesives. Eur J Oral Sci 2005;113:525-30.

[20] Shono Y, Terashita M, Shimada J, Kozono Y, Carvalho RM, Russell CM, et al. Durability of resin-dentin bonds. J Adhes Dent 1999;1:211-8.
[21] Alani AH, Toh CG. Detection of microleakage around dental restorations: a review. Oper Dent 1997;22:173-85.

[22] Proenca JP, Polido M, Osorio E, Erhardt MCG, Aguilera FS, Garcia-Godoy F, et al. Dentin regional bond strength of self-etch and total-etch adhesive systems. Dent Mater 2007:1542-8.

[23] Ferracane JL, Berge HX, Condon JR. In vitro aging of dental composites in water-effect of degree of conversion, filler volume, and filler/matrix coupling. J Biomed Mater Res 1998;42:465-72.

[24] Santerre JP, Shajii L, Leung BW. Relation of dental composite formulations to their degradation and the release of hydrolyzed polymeric-resin-derived products. Crit Rev Oral Biol Med 2001;12:136-51.

[25] Hashimoto $M$, Ohno $H$, Sano $H$, Tay FR, Kaga M, Kudou Y, et al. Micromorphological changes in resin-dentin bonds after 1 year of water storage. J Biomed Mater Res 2002;63:306-11.

[26] Radovic I, Monticelli F, Papacchini F, Magni E, Hafiz Cury A, Vulicevic ZR, et al. Accelerated aging of adesive-mediated fiber post-resin composite bonds: a modeling approach. J Dent 2007;35:683-9.

[27] Carvalho CA, Monticelli F, Cantoro A, Breschi L, Ferrari. M. Push-out bond strenght of fiber posts luted with unfilled resin cement. J Adhes Dent 2009;11:65-70.

[28] Mallmann A, Borges Jacques L, Valandro LF, Muench A. Microtensile bond strength of photoactivated and autoplymerized adhesive systems to root dentin using translucent and opaque fiber-reinforced composite posts. J Prosthet Dent 2007;97:165-72.

[29] Mazzoni A, Marchesi G, Cadenaro M, Di Lenarda R, Ferrari M, Breschi L. Pushout stress for fibre posts luted using different adhesives strategies. Eur J Oral Sci 2009;117:447-53. 